\title{
Sustainable urban life in skyscraper cities of the $21^{\text {st }}$ century
}

\author{
M. M. Ali \\ School of Architecture, \\ University of Illinois at Urbana-Champaign, USA
}

\begin{abstract}
Construction of new skyscrapers is a global phenomenon and is likely to continue in the $21^{\text {st }}$ century. The process of rapid urbanization is most prevalent in developing countries with exploding population and where governments are already striving to improve their citizens' quality of life. In some cities of the industrialized world as well, there is a steady growth of new skyscrapers. The demands for rapid expansion and restructuring of cities often results in poor quality, speedy construction, and the short-term return on investments over livability and a sustainable urban life. This paper emphasizes that well-planned skyscrapers in cities can reduce the demands placed on agricultural land and natural resources and create an enjoyable and sustainable living environment.
\end{abstract} Keywords: tall buildings, cities, urban livability, sustainability, urbanization.

\section{Introduction}

Tall building as a building type is a technological innovation of the 19th century in response to the economic, industrial, and social changes. Chicago and subsequently New York were the birthplaces of commercial tall buildings beginning at the end of 19th and early 20th centuries. Globalization, growing population, and rapid economic development in East Asian countries during the 1980 s and 1990s caused this building type to become widely employed. Currently, Middle Eastern countries are greatly investing in urban developments, and cities are utilizing tall buildings for urban growth albeit somewhat impeded by the ongoing economic recession.

Majority of the world's population will live in urban centers by 2015 and about 60 percent will be urban by 2030 [1]. In 2050, over 80 percent of the world 


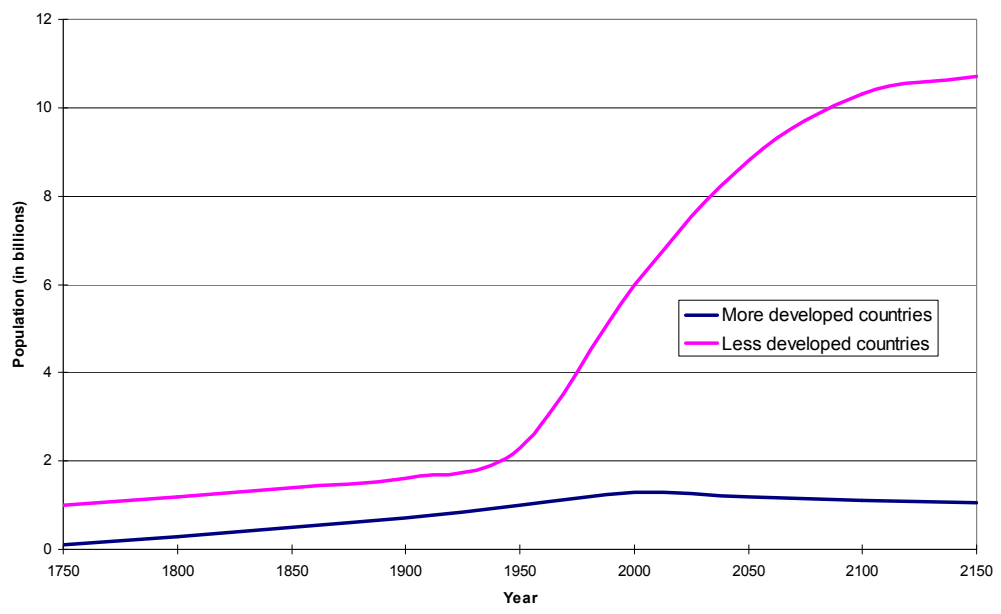

Figure 1: $\quad$ Timeline of global population growth and projection [2].

Table 1: $\quad$ Population growth by world area.

\begin{tabular}{|c|c|c|c|c|c|c|c|}
\hline \multirow[b]{2}{*}{ Area } & \multicolumn{3}{|c|}{$\begin{array}{c}\text { Estimated Population in } \\
\text { Millions }\end{array}$} & \multicolumn{4}{|c|}{ Predicted Population in 2050 in Millions } \\
\hline & 1950 & 2000 & 2003 & Low & Medium & High & $\begin{array}{c}\text { Const } \\
\text {-ant }\end{array}$ \\
\hline Africa & 221 & 796 & 851 & 1516 & 1803 & 2122 & 3279 \\
\hline Asia & 1398 & 3680 & 3823 & 4274 & 5222 & 6318 & 7333 \\
\hline $\begin{array}{l}\text { Latin America and } \\
\text { the Caribbean }\end{array}$ & 167 & 520 & 543 & 623 & 768 & 924 & 1032 \\
\hline North America & 172 & 316 & 326 & 391 & 448 & 512 & 453 \\
\hline Oceania & 13 & 31 & 32 & 40 & 46 & 52 & 58 \\
\hline World & 2519 & 6071 & 6301 & 7406 & 8919 & 10633 & 12754 \\
\hline
\end{tabular}

population will live in urban centers when the projected world population reaches 9 billion; at this time all major cities, particularly those in Asia, Africa and Latin America, will have enormous populations, ranging from 30 million to 50 million or even more. Fig. 1 shows the timeline of population growth within the last two centuries in developing and developed countries, and projections for the next two [2]. Note that the population increased dramatically from 1950 onward particularly in developing countries, which also corresponds to the surge of new tall buildings after the Second World War, especially in the US which experienced an economic boom during that period.

Among other reasons, two are paramount for the development of vertical architecture. First, the exploding population, largely urban, creates an increasing demand for tall buildings. In countries where arable land is scarce or threatened by development, disappearing agricultural land must be protected from further development. Table 1 presents population growth projection by major world areas, and it is evident that the highest growth will occur in Africa and Asia [1]. 
Second, creating vertical density has its inherent logic. Agglomeration improves the ecological environment and contributes to environmental economy. Clustering of buildings in the form of tall buildings is therefore recognized as efficient in terms of transportation and reducing the carbon footprint.

\section{Urbanization in the vertical age}

Tall buildings are integrally connected with a city and its growth because they are responses to unique development conditions found within an urban environment. Most cities just grow. The final form and texture of an expanding city depends on a number of factors such as the availability of land, preferential balance between public and private transport, population pressures, strength of planning and development regulations, the availability of urban services, existing infrastructure, and future plans. The city is a resilient and complex organism capable of absorbing new built intensities inserted into its fabric. More compelling is the view that the city is a marketplace of ideas, a place in which the very ideas of congestion and expansion are intrinsic to its functions and its vitality [3].

\section{Tall building design drivers}

The social, political, psychological, and cultural effects influence the design of tall buildings. Social and political changes such as growing population, development and transformation of information technology, communication systems and stable political governments are key elements of social and political environment of a city.

\subsection{Contextual factors and importance of place}

Tall buildings serve specific functions in meeting urban needs. These functions can be categorized as: commercial, residential, industrial, institutional, public assembly, special purpose, and multi-use. Usually tall buildings are clustered according to the function, providing concentration of use within an urban area. Multi-use tall buildings where typically commercial and residential uses are mixed can also have an impact on the historical heritage of buildings and spaces. It is particularly important that they contribute harmoniously and do not seem to be imposed on the existing environment. Site characteristics, local culture, history and traditions must be considered in the planning phase. Cultural representation is becoming evident in the recent examples of tall buildings, especially in East Asia and the Middle East $[4,5]$.

\subsection{Environmental factors}

Building environment, such as urban topology, topography, climate, wind, and seismic factors directly affect the architectural design of tall buildings and the quality of urban life. External environment affects the overall design, but internal 
environment such as indoor air quality, daylight, and ventilation are also major considerations in determining the quality of life of occupants. Sensible consideration of the use of urban open spaces should take into account the larger urban setting on a macro scale $[6,7]$.

\subsection{Socio-economic factors and urban revitalization}

Tall buildings fit in well where business and organizational structures are geared to large-quantity operations, where building materials are plentiful, and where there is an adequate force of skilled and semi-skilled labor. It could however be the highest-cost solution in a situation where those factors do not exist; the negative impact of these missing resources must be carefully considered. Community development in residential high-rises should be at the heart of the strategies for urban development. During any buildings procurement process, the social needs of the building's neighbors should be high on the agenda. In multiuse buildings, social and economic factors may merge because such buildings accommodate both types of occupancies and their activities. Banks, retail, recreation facilities, etc. in the same complex facilitates interaction of people in a community. Large lobbies and atrium encourage more community interaction.

The major contribution of a tall building is its significance to the volumetric dimensions of an urban space [4]. A city may be developed according to a master plan which anticipates its growth. As it grows, however, the need for remodeling eventually arises for a larger or smaller part of the city. This need could be economic, social, or environmental in nature. The traditional view of the city as a territorial economic engine should be modified to a site of spatially stretched economic relations to open up a rich ecology of urban life [8]. The fundamentals that decide the nature and form of revitalization are density of land ownership, employment densities in the urban core, social values in the urban core, and role of public and private sectors. Two widely different approaches have been used with varying degrees of success in the remodeling of existing cities - urban renewal and planned large-scale developments [5]. High-rise developments may also improve existing dilapidated areas of the city that often are sources of social inequalities in the form of "social brownfields". Urban regeneration is possible in such areas by inserting well-planned and well-designed high-rise buildings with a beautified surrounding landscape. This is a new trend in some American cities to attract young couples, empty nesters, and retirees to the city center where many amenities are available. In some situations social integration of different economic classes is also possible by high-rise developments and communities.

\section{Planning and change}

The tall building type presents an entirely new form, user, and technological problems that cannot be solved by exclusively delving into historical precedents.

Clearly, some form of governmental planning control of intensive developments becomes essential. The strategic plan is one mechanism to control tall building development, to direct intensification of development, and to 
encourage the city's overall urban design policies to be used by city planners. Current information technologies allow for improved planning, visualization and simulation of growth, land use, and infrastructure control. Geographic Information System (GIS) technology is effectively utilized for research, development, implementation, and monitoring of the planning efforts. Graphical interface to complex sets of data, mapping, and three-dimensional visualization offer simplified analysis of complex sets of factors. Virtual cities in conjunction with GIS offer navigable environment and effective digital simulation of real cities, which give planners and designers an opportunity to visualize unbuilt spaces and interaction with the existing infrastructure.

\section{Urban services}

In the urban core where there is greater density and where design choices are more constrained, there may be fewer options. Where there are no tall buildings exist at all, great care must be exercised before making such a decision. The ability of a city or community to support and sustain its current population and anticipated growth is directly related to its infrastructure of transportation, utilities, and services [5]. If the infrastructure is too small, it cannot sustain added burden as the city grows in area and population. If it is too large, it is too costly to maintain relative to the populace or geographic area it serves. Good planning involves predicting and coordinating urban growth with its infrastructure system so that they can grow incrementally together over time. If provision is not made with the foreseeable future in mind for the large amounts of traffic generated by tall buildings, the existing system will quickly be overtaxed and subsequent high municipal costs will result as the city attempts to solve the problems thus created. On the other hand, as tall buildings create concentrations of people, their concomitant development with an urban transportation system that is sustainable can produce significant economies both for the developer and the city.

\section{Case studies}

Three case studies are presented to briefly illustrate the interdependence of tall buildings and cities to generate a harmonious balance between them resulting in better urban life in their respective regional and local contexts.

\subsection{Jakarta: a megacity in a developing country}

Jakarta is one of the largest cities in the world, having a population of more than 20 million. It is located in island-country Indonesia that struggles with overpopulation, inadequate housing, employment, transportation and environmental quality [9].

Tall buildings have been widely used for commercial and residential functions in Jakarta to address the issues of land scarcity and enormous population, as seen in fig. 2 . Three economic sectors are rapidly developing in 


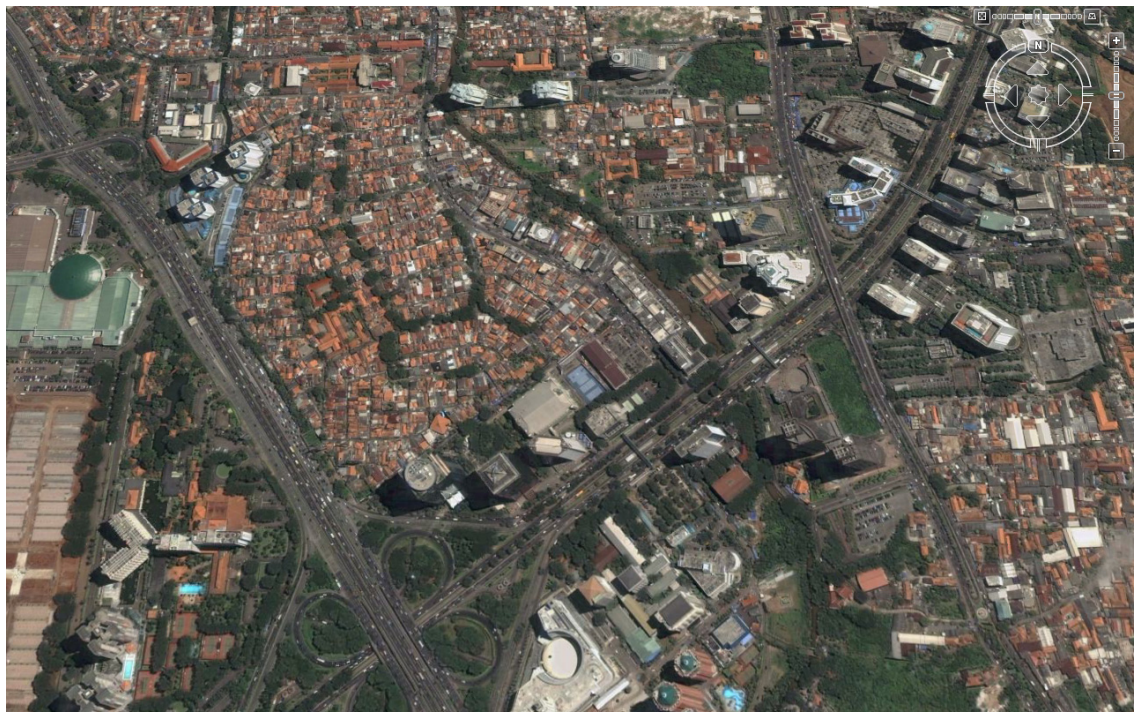

Figure 2: Dispersed locations of high-rise buildings in Jakarta and relationship to low-rise (Source: Google Earth).

Jakarta-manufacturing, mostly located in the periphery; finance, located in the urban core; and real estate, including large-scale housing and new town development projects in the outskirts, and offices, hotels, residential tall buildings and retail in the center. The development efforts have been greatly supported by the existing infrastructures, including the international airport, seaports, telecommunication, electricity, water supply, local transportation, and social amenities. The development of large-scale housing projects and new towns in the periphery has intensified the interaction with the urban core, since the new developments are socio-economically dependent on the center. This has increased transportation problems and congestion.

\subsection{Dubai: international commercial center}

Dubai is located on the Persian Gulf and is one of the fastest growing cities in the world [10]. Recently it has transformed from a traditional to a modern economy. Development of Dubai as a major commercial center required the identity of this urban environment to represent prosperity, wealth, and globalization. Urban development is a major concern for policy makers, planners, public officials, and environmental advocates. Rising prices of oil have resulted in immense influx of commercial activity in this region, resulting in unprecedented growth and expansion. According to Davids et al. [11], "A casual observer in Dubai would say that this was simply a shallow display of wealth fuelled by selling oil. However, living and working in Dubai we discover a more startling reality, that it is an act of Nation Building. For a nation being born, these built forms can be as important as grains of sand to an oyster. They provide a sense of place where 


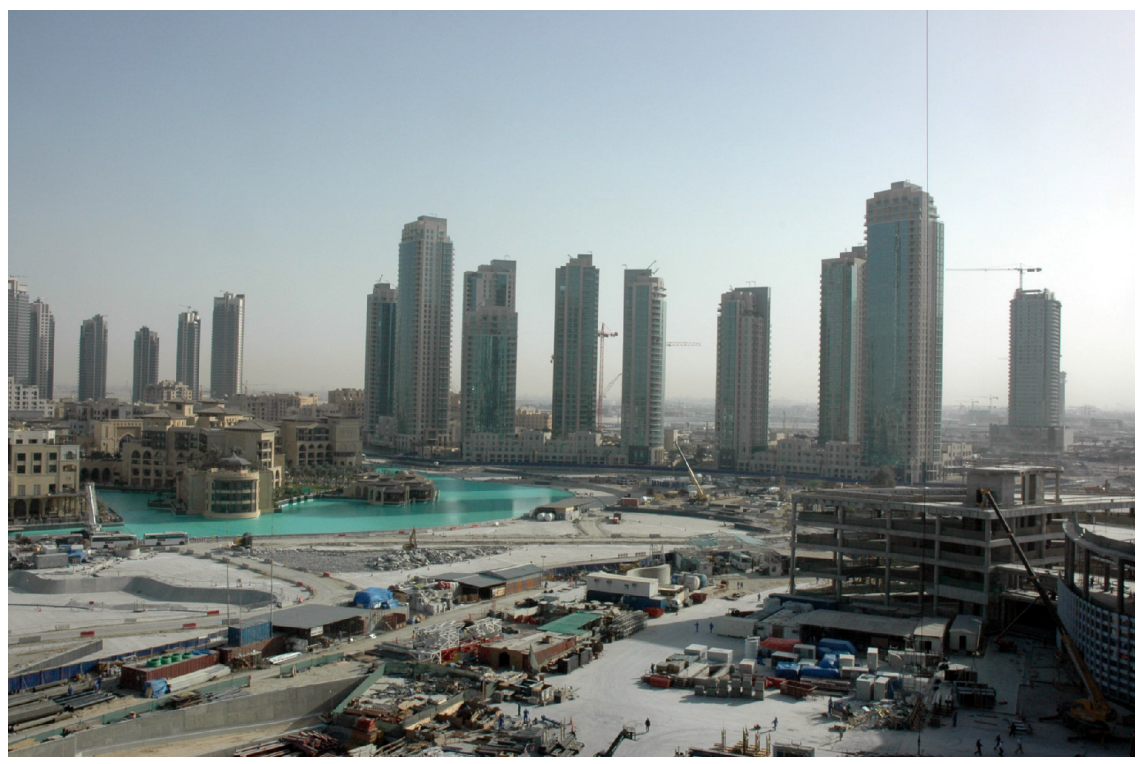

Figure 3: Tall building construction in Dubai (Credit: Paul Armstrong).

such a sense did not exist, and something to share where a wider sense of community has no roots." Tall buildings are the image of Dubai today, as seen in fig. 3. Rapid development, economical growth, low construction cost, and globalization have caused this particular type to be widely adopted.

Some people have observed that Dubai has been welcoming supertall and iconic buildings (such as Burj Al Arab and Burj Dubai) and planning other ambitious mega-projects (such as the Waterfront City) too rapidly without adequate consideration of the infrastructure to its future sustainability. A reference may be made to other cities near Dubai. Abu Dhabi and Bahrain are to a lesser extent following Dubai's lead. We will witness more tall buildings in these cities. Amman has pursued distinctive development that demonstrated both the interactions of global market forces and local conditions [12].

\subsection{Songdo City: a modern sustainable city}

New Songdo City is located in Incheon, about 60 kilometers from Seoul. It is a new, master-planned development planned and designed as an international business district on reclaimed land. It is currently under construction, and will be connected to Incheon International Airport. It has been designed for 75,000 residents and 300,000 commuters. Being the first international real estate development in South Korea's history, it is poised to help South Korea to becoming the commercial epicenter of North Asian regional markets.

Korean government initiated a plan to develop International Free Economic Zone (IFEZ) that links Northeast Asia to global economies. Convenience and 
accessibility in transportation were the key elements for site location. The plan for the city includes commercial, residential, mixed and green space, as seen in fig. 4 . The city includes $40 \%$ of open green space, where about one half of that area is located in the center, and the other on the outskirts.

The master plan promotes technology, sustainability and internationally designed buildings. The major factors influencing Songdo City development are sustainable development practices and integration of urban planning, infrastructure engineering, and architecture. Long-term sustainability is considered to be future-oriented design, where systems should be adaptable to changing needs such as site planning, energy, waste and the impact on larger environment. Social aspects are also important, since the effort is to design transit-oriented development that creates social vibrancy and connectivity, embraces culture, and creates economic creativity. The planning of the city encompasses a variety of densities, ample green space, streetscapes with character and rhythm, sustainable transportation and adequate infrastructure. The neighborhoods of the city extend out from both sides of the city center. Mixeduse projects and lower scale commercial development buffer the outlying residential neighborhoods. The transition of land use from high-rise commercial to mid-rise residential/commercial to low-rise residential/amenity is designed to create a vibrant urban environment and a sustainable urban life.

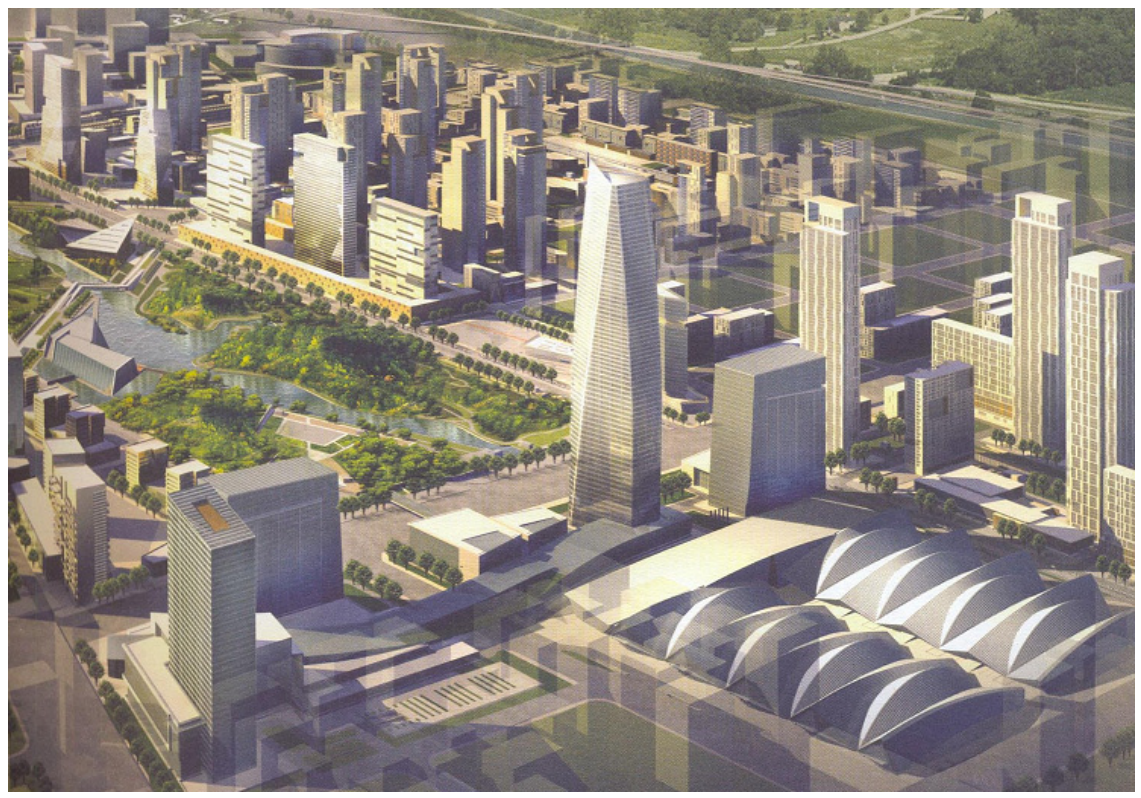

Figure 4: Tall buildings and open space in New Songdo City (Credit: Gale International/KPF Associates PC). 


\section{Integrating cities and tall buildings}

Integration of cities and tall buildings is crucial for sustainable cities of the $21^{\text {st }}$ century. Well planned cities have tall buildings at appropriate locations, since this particular building type reduces the demand placed on natural resources. The performance of both tall buildings and cities can be enhanced by appropriate measures, such as resource conservation, waste reduction, and infrastructure planning. Improved urban life depends on a city in balance based on the holistic urban design methodology. Both tall buildings and cities should demonstrate reciprocity in which they mutually benefit each other, and equivalence in which one of them does not outpace the growth of the other. Integration of tall buildings and cities is the key to a better and sustainable urban life.

Tall buildings give cities an identity, while cities determine how a tall building can be viable and be constructed to derive a meaning. As a land-use strategy, tall buildings maximize building area with a minimum physical footprint. Extreme compactness drives environmental economy. When developments expand vertically, public space, agricultural lands, and wilderness remain untouched. Commercial and residential towers free the ground plane for the development of ample green space within density that supports connectivity and social vibrancy.

For a city to be sustainable, it must consider how it will grow and develop planning guidelines for the efficient utilization of its land mass. New ways of integrating city design with the process of economic and social change need further exploration [13]. A sense of well-being in tall buildings is associated with the availability of ample daylight, connection with outside environment and the view. The ability to control the immediate environment improves overall satisfaction of occupants. For high-rise buildings in particular, transportation, safety, and the feeling of being part of the natural environment on the ground are keys to an enjoyable and satisfying urban life.

\section{Greening of existing cities}

The challenge of climate change has pervaded all sectors of the built environment and the urban setting that contains it. Many existing cities have super-high density overloaded with sensory, physical, and digital imposition and information and have begun to emulate a vibrant, sustainable futuristic city model. Green or sustainable design is generally being focused on new and future buildings. Arguably, however, upgrading existing buildings to reduce energy consumption and carbon expenditure will make a great difference. This is particularly true for tall buildings, with their high embodied energy as well as operational energy and complexity of issues to be tackled for future demolition. Some approaches to accomplish this goal are to make existing tall buildings sustainable to produce energy, replacing existing façades with high performance ones, produce power from wastes in skyscrapers, adding green terraces and roofs on buildings where possible to reduce heat island effect, increasing green 
parklands, drawing energy from geothermal, nuclear, and renewable energy sources, etc.

The Chicago Center for Green Technology is a successful example of renovation in Chicago to achieve the LEED Platinum rating, the highest LEED designation. Architect Adrian Smith prepared a plan for Chicago that included the Sears Tower (renamed Willis Tower). He prepared an urban matrix that included walkable school districts in cities to draw residents from suburbs back into the city, green roof, pedestrian-friendly routes, etc. Clustered buildings, linked towers, community facilities like restaurants, stores, laundry, cost-cutting for infrastructure systems, mobility, etc. are the components of this matrix.

To enhance the quality of cities and to remake them into sustainable cities, urban designers and architects should plan for better density resulting in sustainable urban life. Making tall buildings sustainable along with improved mass rapid transport system will improve urban life and bring more people to cities.

\section{The wave of the future}

As cities grow outward towards suburbia connected by expressways and other transit systems, they also tend to grow towards one another as development occurs along transportation corridors. The resulting urban fabric comprises cities, suburbs, and satellite and island cities that merge into one undifferentiated urban system. Cities of the future will most likely expand to the pressures of exchanging information through digital technology. As cities grow in density, they will have to grow vertically, as their horizontal expansion becomes constrained by limitations imposed by the optimum horizontal scale for the functionality of cities. Even farming and other agricultural production activities will probably grow vertically through "vertical farms." Urban design will gradually embrace the vertical dimension of cities. Conventional theories and ideas of urban design "could be reconfigured laterally and transposed vertically. Urban design concepts meant for the horizontal plane will be flipped to a highrise condition and reinterpreted as vertical propositions" [14]. Future cities will no longer be viewed as flat on ground but a composite of horizontal and vertical architecture. The cityscape will transform into skyscape.

Looking at the negative side, there may be some out-of-balance cities lacking functionality in the underprivileged countries. Slum dwelling population and lack of sanitation in the urban areas of these countries may reach alarming proportions resulting in problems of chronic unemployment, pollution, ill health, crime, and other anti-social activities. Another major crisis for future cities in the developing world is the functionality and problems related to complex infrastructure. Transportation gridlock on city streets will reach unbearable proportions. Water and power shortages will be major problems. As the developing world becomes more urbanized, the water crisis will deepen. On the other hand, looking at the positive side, if the developing world gets economically prosperous along with the developed world, a different picture may 
emerge. In a prosperous world with the positive impetus of globalization, some of these cities will flourish and build upward resulting in 3D skyscraper cities.

In developed countries, the growth of population is limited and manageable. Renewable natural sources will be explored. Innovations in transportation will be pursued. In old cities the industrial brownfields will be regenerated and renewed. In general, both in economically prosperous developing countries and the industrialized developed countries, layered 3D cities with tall buildings connected by bridges in the sky will continue to emerge. In early $20^{\text {th }}$ century Antonio Sant'Elia envisioned future cities as multi-level, interconnected urban conurbations of high-rise clusters with industrial expressionism [5]. Similar mechanical and industrial visionary design was conceived in Russian constructivism pioneered by Iakov Georgievich Chernikhov, who believed constructive principles are fundamental to human design activity [15].

Layered 3D cities are the likely imagery of the future and architects and urban designers will continue to perfect artifacts in a city in progressive phases of transition, experimentation, and continued search. Recently, architect Steven Holl designed eight 22-story towers for the Linked Hybrid project accommodating 750 apartments in a cluster interconnected by bridges at the $20^{\text {th }}$ and $22^{\text {nd }}$ floors accommodating school, swimming pool, etc. It can be viewed as architecture in which connections are made both at the ground level and in the sky. It represents a layered and connected urbanism embodying mixed-use zoning.

\section{Concluding remarks}

Design simplicity and logic of vertical density will likely prevail in the future to create sustainable and resilient cities in conjunction with exploration and experimentation of new urban forms. New questions regarding environmental and interference effects, property and space ownership, regulations, real estate marketability, etc. will arise. The dynamics of linking vertical and horizontal spaces will need acumen, imagination, and a higher degree of collaboration of parties and stakeholders. Eventually, tall buildings that are adaptive to the prevailing technology of the time, local culture and context, the environment, and that are cost-effective in creating an organic lifestyle similar to the ground plane, will triumph over those that deviate from these fundamental attributes. They will be the catalysts for creating sustainable urban life in future skyscraper cities.

\section{References}

[1] United Nations, Future world population growth to be concentrated in urban areas. United Nations Population Division Report, United Nations: New York, NY, 2002.

[2] United Nations, World Population Prospects: The 1998 Revisions, United Nations: New York, NY, 1998.

[3] Ali, M. M. \& Armstrong, P. J., (eds). Architecture of Tall Buildings, McGraw-Hill: New York, NY, 1995. 
[4] McNeill, D., Skyscraper geography, Progress in Human Geography, 29(1), pp. 41-55, 2005.

[5] Beedle, L., Ali, M. M. \& Armstrong, P. J., The Skyscraper and the City: Design, Technology, and Innovation, Edwin Mellen Press: Lewiston, NY, 2007.

[6] Zacharias, J., Stathopoulos, T. \& Wu, H., Microclimate and downtown open space activity, Environment and Behavior, 33(2), pp. 296-315, 2001.

[7] Gissen, D., Big \& Green: Toward Sustainable Architecture in the $21^{\text {st }}$ Century, Princeton Architectural Press: Princeton, NJ, 2003.

[8] Amin, A. \& Thrift, N., Cities: Reimagining the Urban, Polity: Oxford, UK, 2002.

[9] Cybriwsky, R. \& Ford, L. R., City profile Jakarta, Cities, 18(3), pp. 199210, 2001.

[10] Al Marashi, H. \& Bhinder, J., From the tallest to the greenest-paradigm shift in Dubai, Proc. of the CTBUH $8^{\text {th }}$ World Congress, Tall and Green: Typology for a Sustainable Urban Future, Dubai, UAE, ed. A. Wood, CTBUH: Chicago, IL, pp. 77-83, 2008.

[11] Davids, A., Wongso, J., Popovic, D. \& McFarlane, A., A postcard from Dubai - design and construction of some of the tallest buildings in the world, Proc. of the CTBUH $8^{\text {th }}$ World Congress, Tall and Green: Typology for a Sustainable Urban Future, Dubai, UAE, ed. A. Wood, CTBUH: Chicago, IL, pp. 152-157, 2008.

[12] Abu-Ghazalah, S., Skyscrapers as an instrument for economic development: the case of Amman", Architectural Research Quarterly, 11(1), pp. 81-88, 2007.

[13] Barnett, J., The Elusive City: Five Centuries of Design, Ambition and Miscalculations, Harper \& Row: New York, NY, 1986.

[14] Yeang, K., Reinventing the Skyscraper: A Vertical Theory of Urban Design, Wiley-Academy: Chichester, UK, 2002.

[15] Cooke, C., Chernikhov-Fantasy and Construction: Iakov Chernikhov's Approach to Architectural Design, Architectural Design AD Edition: London, U.K. (distributed in the U.S. by St. Martin's Press: New York, NY), 1984. 